\title{
$\widehat{A}$ Madridge \\ madridge Journal of Nursing \\ interconnecting Scientific world
}

Review Article

Open Access

\section{Defining Vulnerability}

\author{
Emily Havrilla \\ Assistant Professor, Passan School of Nursing, Wilkes University, USA
}

\section{Article Info}

\author{
*Corresponding author: \\ Emily Havrilla \\ Assistant Professor \\ Passan School of Nursing \\ Wilkes University \\ 84 W. South St. \\ Wilkes-Barre, PA 18766 \\ USA \\ Tel: 570-408-4069 \\ E-mail: emily.havrilla@wilkes.edu
}

Received: August 16, 2017

Accepted: August 18, 2017

Published: August 24, 2017

Citation: Havrilla E. Defining Vulnerability. Madridge J Nurs. 2017; 2(1): 63-68.

doi: 10.18689/mjn-1000111

Copyright: (c) 2017 The Author(s). This work is licensed under a Creative Commons Attribution 4.0 International License, which permits unrestricted use, distribution, and reproduction in any medium, provided the original work is properly cited.

Published by Madridge Publishers

\begin{abstract}
There is an increased awareness of the needs of vulnerable individuals and populations in the discipline of nursing. In order to meet the healthcare needs of the vulnerable, nurses need to understand the multiple implications of vulnerability. The term "vulnerability" is widely used and embedded in the nursing vocabulary, yet it remains a difficult concept to define. The concept of vulnerability has developed over the last thirty-five years broadening to encompass aspects of risk and resiliency. Theories of vulnerability include personal and societal factors. The definition of vulnerability, grounded in the literature and prevalent theories of vulnerability, is used to describe the role of nursing in the care of the vulnerable. The nursing process is used to assess vulnerability and facilitate a resilient response at the individual and community levels.
\end{abstract}

Keywords: Vulnerability; Concept; Definition; Theory; Nursing process.

\section{Defining Vulnerability}

The discipline of nursing and the healthcare community have become increasingly aware of the needs of vulnerable individuals and populations. In the United States, vulnerability has been linked with health disparities, resulting in a subsequent focus on national health equality [1]. The National Institutes of Health (NIH) and the National Institute of Nursing Research (NINR) both have research goals that include decreasing health disparities $[2,3]$. The national healthcare agenda, articulated in Healthy People 2020, integrates a focus on decreasing health disparities across the goals [4]. Nursing is faced with the challenge of addressing the needs of the vulnerable. What then is the definition of vulnerability and how should the concept of vulnerability be integrated into nursing care? The aim of this article is to provide an overview of vulnerability and offer direction for the development of nursing interventions in the care of the vulnerable.

\section{Definition of Vulnerability}

Vulnerability, as a concept, has evolved dramatically over the last thirty-five years. Prior to its identification as a concept by Rose and Killien in 1983, vulnerability was a descriptive term associated with risk, often phrased as "vulnerable to". With their distinction between personal and environmental factors and the associated terms of vulnerability and risk, Rose and Killien initiated the examination of the concept of vulnerability [5]. Nursing literature throughout the 1980's reflected attempts to define and describe vulnerability $[6,7,8]$.

In the 1990's the concept broadened with the seminal, sociologic work of Aday to include community and individual perspectives related to physical, psychological and social health, as well as the associated resources to respond [9]. During this time period nurse scientists viewed vulnerability along a continuum and its relationships to other concepts were examined $[10,11,12,13,14]$. Moving into the $21^{\text {st }}$ century, vulnerability was 
considered within the context of changing demographics and multicultural, intercultural, and intracultural issues [15]. There was a shift in the concepts that were examined in relation to vulnerability. These included marginalization, social connectedness, and health disparity $[16,17,18,19,20]$.

As the meaning of vulnerability has evolved, the view has shifted to one of openness and vulnerability as opportunity. Capabilities, resilience, and resourcefulness are now included as key factors that influence the outcomes associated with vulnerability $[21,22,23]$. Post modern reconstruction of vulnerability describes movement from immobility to growth and integration [24]. The concept of vulnerability has evolved to the point that it is viewed as having transformative power [25].

Moving forward into the $21^{\text {st }}$ century, the usage of the terminology associated with vulnerability is fluid in the literature related to discipline and point of view. Concurrent meanings of vulnerability continue to exist; however, the term is often preceded by a descriptive adjective such as "societal" vulnerability or "personal" vulnerability, implying a general recognition of the multiple meanings of vulnerability. Based on the review of literature, vulnerability may be defined as: a state of dynamic openness and opportunity for individuals, groups, communities, or populations to respond to community and individual factors through the use of internal and external resources in a positive (resilient) or negative (risk) manner along a continuum of illness (oppression) to health (growth). Vulnerability is a universal concept. Everyone is potentially vulnerable and will experience vulnerability to varying degrees. Depending on the view of vulnerability, the primary focus may be on health and illness or it may be on oppression and growth as linked to personal or societal resources.

Because of this extensive view of vulnerability, many populations may be considered vulnerable. In Aday's original text [26], the following populations were considered vulnerable: high-risk mothers and infants, chronically ill and disabled, persons with AIDS, mentally ill and disabled, alcohol or substance abusers, suicide or homicide prone, abusing families, homeless, and immigrants and refugees. With the increasing awareness of populations who experience health disparities and marginalized populations, this list may be expanded and re-defined on an ongoing basis. Vulnerability is a dynamic process and may be experienced by anyone.

\section{Theories of Vulnerability}

Vulnerability has been used historically as a descriptive term and it appears as a concept in multiple disciplines [27, $28,29,30,31]$. Several theoretical frameworks of vulnerability are important for guiding and directing nursing care. These theories either present the concept within the framework of the nursing paradigm or they serve as seminal theory which subsequently has influenced the development of nursing theory about vulnerability.

Rose \& Killien not only first identified vulnerability as a concept; they also examined key aspects of vulnerability.
Analysis of previous literature in a variety of fields facilitated the distinction between risk and vulnerability. According to Rose \& Killien, risk is interpreted as a function of the environment, with the environment including the physical surroundings, direct and indirect influences, and sociocultural environment. Vulnerability is a function of the individual, influenced both by inherent and acquired factors. Both the individual and the environment contribute to health outcomes, where they dynamically affect each other via a transaction. Health is the result of interaction between an individual and their environment. Characteristics of vulnerability and risk and the transaction between them need to be considered when decisions in nursing practice and nursing research are made. Theoretical propositions include: differentiation between the concepts of risk and vulnerability can facilitate the diagnosis and treatment of human responses to actual and potential health problems; characteristics of both the individual and the environment contribute to health or illness, one affects the other in a dynamic way [5].

Social vulnerability has developed from a variety of fields, with each field defining the concept differently. The theory that reverberates throughout the literature and that has been frequently cited by nurse scientists is the work of Aday [9]. Risk factors, predictors of risk, are described from individual and community perspectives and include social status, social capital, and human capital. Social status includes age, sex, race and ethnicity; social capital includes family structure, marital status, voluntary organizations, social networks; and human capital includes schools, jobs, income, and housing. Vulnerable populations experience relative risk of poor physical, psychological, and/or social health. Within this framework there is always a chance of an adverse healthrelated event and everyone is potentially at risk of poor physical, psychological and/or social health. Propositions: everyone is potentially vulnerable (at risk); risk (relative risk) of vulnerability is greater for those with the least social status, social capital, and human capital resources to prevent or ameliorate the origins and consequences of poor physical, psychological, or social health $[9,26]$.

The most noteworthy nursing conceptual model of vulnerable populations is that developed by Flaskerud and Winslow [18]. Vulnerable populations are defined as social groups who have an increased relative risk or susceptibility to adverse health outcomes. Causes of susceptibility include low social and economic status and lack of environmental resources. Flaskerud and Winslow recommend a community health perspective and state the model focuses on the responsibility of communities to provide opportunities and resources to achieve and maintain health [18].

In the Vulnerable Populations Model, resource availability, relative risk, and health status are related. The model builds on Aday's theory of vulnerability related to relative risk. Resource availability includes socioeconomic and environmental resources, defined as human capital, social connectedness, and social status. Health status is indicated by disease prevalence and morbidity and mortality rates. The 
authors view the model as having wide application for nursing research, practice, and ethical and policy analysis with the potential to affect resources, relative risk, and health status directly and indirectly. Propositions: lack of resources increases relative risk; increased exposure to risk factors leads to increased morbidity and mortality in a population group; morbidity and mortality in a community may feed back into resource availability and further deplete the availability of resources [18].

Other theories of vulnerability found in the literature are less widely known. Lessick, Woodring, Naber, and Halstead [13] developed a conceptual model of vulnerability that was intended to be relevant to perinatal and neonatal nursing. Vulnerability is the net result of an individual's assets and liabilities interacting with specific environmental assets and liabilities, which then determine the likelihood of health or illness. Within this model, a person is the vulnerable system comprised offour dynamic dimensions: biologic, psychological, social, and cognitive. The person is in constant interaction with a changing environment, influenced by and influencing the environment. Individual assets and liabilities are dynamic, originating from constitutional equipment, contextual modifiers, and operational environment. Constitutional equipment is determined by genotype and development. It includes intactness of body parts, temperament, and susceptibility to illness and directly affects the vulnerability of an individual. The environment is composed of phenomenal stimuli (external conditions), personal stimuli (internal conditions), and social stimuli (occur between individual and others). Contextual modifiers are biopsychosocial-cognitive factors that change, reduce, or amplify vulnerability. The operational environment consists of phenomenal, personal, and social stimuli that impact an individual's vulnerability throughout their life. Vulnerability is dynamic, expressed as behavior, determining the location of individuals along a health-illness continuum Propositions: an individuals vulnerability level is dynamic and can alter as changes take place in the person, environment, or both; each individual has a threshold at some level of vulnerability beyond which illness can occur [13].

Another theory of vulnerability was developed by Rogers [14]. In this theory, Aday is referenced in defining vulnerable populations as being at risk of poor physical, psychological, and/or social health. Determinants of vulnerability include age, gender, race/ethnicity, social support, education, incomes, and life change. The theories of Rose and Killien, Aday, and Lessick and colleagues are referenced to define personal and environmental components of vulnerability. The model of vulnerability developed is depicted as an equilateral triangle that demonstrates the interaction of environmental supports, personal resources, and vulnerability. The base of the triangle is the continuum of vulnerability. The sides are environmental supports and personal resources in a range from many to few. An individual's vulnerability is determined by identifying the level of environmental support and personal resources, finding their intersection and then drawing a line to the vulnerability continuum. Propositions: degree of vulnerability is related to the outcome of the interaction of personal resources and environmental supports [14].

Theories of vulnerability have originated in many settings. Appleton [10] examined the concept of vulnerability through a qualitative approach as described by health visitors following families in the British National Health Services. Through data analysis, a model describing internal and external stress factors of vulnerability and a continuum of vulnerability was formulated. Families are described as more or less vulnerable throughout their life cycle relative to their ability to cope with stress factors. Vulnerability is a transient, dynamic process and an ambiguous concept. Proposition: vulnerability is a transient concept, occurring along a continuum by which families move in and out of relative to internal and external stress factors [10].

The Theory of Self-Care Management for Vulnerable Populations is an alternate approach to addressing the concept of vulnerability by focusing on self care management and intrapersonal factors to manage illness. Self care management is also influenced by contextual factors. The theory incorporates concepts from the Vulnerable Populations Conceptual Model. People with chronic illness encounter modifiable and non-modifiable factors that may increase their vulnerability. These are related to self-care management and associated levels of health status and quality of life. Proposition: people with a chronic illness encounter both modifiable and non-modifiable factors that may increase their vulnerability [12].

The concept of vulnerability evolved and became broader in nature as it started to include the associated concepts of marginalization and health disparity. One of the first descriptions of vulnerability by Stevens, Hall, and Meleis [32, 33], examined the meaning of vulnerability from the point of view of working women. Vulnerability is not related to social determinants, but rather it originates in daily experiences and incorporates both environmental and personal phenomena. Through a qualitative approach, vulnerability was defined as persons' experiences of being unprotected and open to damage in threatening environments. Narrative themes were identified with vulnerability being cumulative and viewed as a web of contingencies. Propositions: vulnerability is a web of contingencies; vulnerability is cumulative [33].

As the concept of vulnerability expanded, theories relating the concepts of vulnerability and marginalization were developed. Marginalization is defined as the process through which persons are peripheralized on the basis of their identities, associations, experiences, and environments [34]. Seven key properties of marginalization are identified: intermediacy, differentiation, power, secrecy, reflectiveness, voice, and liminality. Vulnerability is the condition of being exposed or unprotected with inherent components of risk and resilience. Each property of marginalization has elements of risk and resilience. Propositions: (intermediacy) human boundaries act as barriers and connections; (diversity) of identities increases with physical and social distance from the 
center; (power) influence is exerted by those at the center of a community over the periphery and vice versa; (secrecy) information is confined to establish interpersonal bonds, maintain trust, and avoid betrayal; (reflectiveness) marginalized persons have subjective experiences that distinguish them from more centrally located community members; (voice) marginalized persons and groups have ways of communicating that distinguish them from those at the center; (liminality) marginalized persons have altered and intensified perceptions of time, worldview, and self-image that characterize and result from marginalizing experiences [34].

This theory was expanded to include the properties of exteriority, constraint, eurocentrism, economic, seduction, testimonies, and hope. Propositions: (exteriority) condition of being outside the dominant system, beyond societal protections and resources; (constraint) bodily restriction experienced in incarceration, entrapment or physical intrusion; (eurocentrism) European and North American values and technologies are viewed as superior to those of exteriorized peoples; (economics) set of contingencies that affects marginalized peoples; access to resources; (seduction) manufacture of desires for material objects that promote the consumer market place and objectification of persons; (testimonies) personal narratives elaborating exteriorized life experiences and survival; (hope) positive view of the future based on concrete efforts toward sociopolitical transformation [35]. The responsibility of nursing is to transform exteriorizing social structures as a function of the sociopolitical dimensions of nursing. This transformative power of vulnerability is found in $21^{\text {st }}$ century literature [25].

\section{Role of Nursing: Facilitating Resiliency}

A synthesis of the definitions and theoretical models of vulnerability reveals a commonality. There is a need to strengthen the capacity to respond to vulnerability. At all levels, augmenting resources will facilitate movement of the individual or population in a resilient direction. Each step of the nursing process for the care of the vulnerable individual or community should include a focus on a resilient response to risk.

\section{Assessment}

The nursing assessment moves beyond a primarily physical assessment related to "risk" of a disease. Elements to include in assessing the ability to respond to vulnerability are a comprehensive assessment of socioeconomic factors and the impact on the individual, the client's coping strategies and plan to respond to issues, the effectiveness of the client's plan, and options for strengthening resources to foster resiliency and decrease risk through individual and programmatic interventions. This type of assessment may also be conducted to determine the ability to respond to vulnerability in families, groups, communities, and populations. Furthermore, assessment of resources to respond to vulnerability is also applicable in nursing care related to disease management and population health.

At the societal level, a thorough community assessment of the available social and human capital would provide information related to the degree of vulnerability and provide a foundation for planning programmatic and community based interventions. Community level data analysis would assist in the identification of patterns of response to vulnerability and provide direction for planning interventions.

\section{Diagnosis}

In formulating a specific nursing diagnosis, the nurse is using clinical judgment to determine a client's response to health conditions or needs [36]. The diagnosis is not "vulnerable to", but now becomes "vulnerable related to". In formally stating vulnerability as a nursing diagnosis, the nurse focuses on the specific factors that are part of the client's vulnerability.

\section{Outcomes}

Outcomes are identified and expressed as short-range and long-range goals. As with other outcomes, they should be specific and measurable. The outcomes articulated should reflect goals that lead to a resilient response to the specific issues of vulnerability.

\section{Intervention}

Congruent with the majority of theoretical frameworks, nursing interventions may be designed at either the personal or societal level to strengthen individual, family, or community resources, thereby facilitating a response to vulnerability in a resilient direction. Many nursing interventions implemented in the care of vulnerable populations inherently increase resilience. Interventions specifically designed with the intended goal of increasing resources to respond to vulnerability have the potential to be more effective.

Strengthening of individual factors such as self-efficacy and coping mechanisms through targeted interventions would facilitate the ability to respond effectively to vulnerability. These may range from education and counseling, to the provision of resources. At the societal level, nurses may advocate for resources and funding support, as well as participate in the development of programmatic solutions designed to augment social and human capital. It is in these types of interventions that the transformative nature of vulnerability is realized.

\section{Evaluation}

Ongoing evaluation of the effectiveness of the interventions implemented will assist in determining the client's vulnerability. A resilient response to vulnerability will be related to the achievement of specific goals. Re-evaluation of the overall plan provides an opportunity for change in interventions. On a community level, continuous evaluation will afford individuals, partners, and stake holders an 
opportunity to change strategies if necessary. Complex community based interventions will require continual oversight and data collection to evaluate the success of programmatic interventions.

Vulnerability is multidimensional with individual aspects difficult to isolate. An individual or community may have many sources of vulnerability and specific issues may be hard to identify. Likewise, interventions may target more than one aspect of vulnerability. For example, food insecurity may lead to the lack of adequate nutrition. Referral to a food pantry although appropriate will not necessarily increase the individual's resiliency. Education regarding meal planning within the food resources accessed through the food pantry and healthy choices within the environment would support better nutritional decisions. An assessment of the community would identify weaknesses in the programming to support food pantries. At the community level, support for food pantries through funding for appropriate facilities and food supplies would decrease the presence of canned and processed food, leading to better nutrition which may be considered movement towards a resilient response.

\section{Conclusion}

The care of vulnerable individuals and communities requires an understanding of the meaning of vulnerability and an appreciation of the complexity of the relationship between vulnerability and individual and societal factors. However vulnerability is defined and understood, nurses are able to implement strategies that are effective in increasing a client's ability to respond to vulnerability. Often strategies at both the individual and community levels are required to facilitate a resilient response to vulnerability. Nursing's ability to respond to vulnerable clients is grounded in educational preparation, research evidence, and community support. An increased focus on the care of the vulnerable in practice, education, research, and health policy advocacy would foster an integrated approach to facilitating resiliency.

\section{Conflict of Interest Statement}

The author declares that there is no conflict of interest.

\section{References}

1. Nyamathi A, Koniak-Griffin D, Greengold BA. Development of Nursing Theory and Science In Vulnerable Populations Research. Annu. Rev. Nurs. Res. 2007; 25: 3-25.

2. NIH-wide Strategic Plan Fiscal Years 2016-2020: Turning Discovery Into Health. National Institutes of Health.

3. The NINR Strategic Plan: Advancing Science, Improving Lives. National Institute of Nursing Research. 2016.

4. Healthy people 2020. Healthy people. 2017.

5. Rose $\mathrm{MH}$, Killien M. Risk and vulnerability: a case for differentiation. Adv. Nurs. Sci. 1983; 5(3): 60-73.

6. Copp LA. The Nurse as Advocate For Vulnerable Persons. J. Adv. Nurs. 1986; 11(3); 255-263. doi: 10.1111/j.1365-2648.1986.tb01246.x
7. Rose MH. The concepts of coping and vulnerability as applied to children with chronic conditions. Issues. Compr. Pediatr. Nurs. 1984; 7(4-5): 77-186. doi: $10.3109 / 460868409006341$

8. Stember ML, Stiles MK, Rogers S. Severity of an dvulnerability to health problems in school-age children. Issues. Compr. Pediatr. Nurs. 1987; 10: 263-272. doi: 10.3109/01468709094348

9. Aday LA. At risk in America: The Health and Health Care Needs of Vulnerable Populations in the United States. San Francisco: Jossey-Bass; 1993.

10. Appleton JV. The concept of vulnerability in relation to child protection: health visitors' perceptions. J. Adv. Nurs. 1994; 20(6): 1132-1140. doi: 10.1046/j.1365-2648.1994.20061132.x

11. Cody A. Helping the vulnerable or condoning control within the family: where is nursing ? J. Adv. Nurs. 1996; 23(5): 882-886. doi: 10.1111/j.1365-2648.1996. tb00066.x

12. Dorsey CJ, Murdaugh $\mathrm{CL}$. The theory of self-care management for vulnerable Populations. J. Theory. Constr. Test. 2003; 7(2): 43-49.

13. Lessick $M$, Woodring BC, Naber $S$, Halstead L. Vulnerability: a conceptual model applied to perinatal and neonatal nursing. J. Perinat. Neonatal. Nurs. 1992; 6(3):1-4.

14. Rogers AC. Vulnerability, health and health care. J. Adv. Nurs. 1997; 26(1): 65-72.

15. Hall JM. Marginalization and symbolic violence in a world of differences: war and parallels to nursing practice. Nurs. Philos. 2004; 5(1): 41-53. doi: 10.1111/j.1466-769X.2004.00165.x

16. Flaskerud $\mathrm{JH}$. Health disparities research: from concept to practice. Commun. Nurs. Res. 2002; 35: 3-13.

17. Flaskerud JH, Lesser J, Dixon E, et al. Health disparities among vulnerable populations: evolution of knowledge over five decades in nursing research publications. Nurs. Res. 2002; 51(2): 74-85.

18. Flaskerud JH, Winslow BJ. Conceptualizing vulnerable populations healthrelated Research. Nurs. Res. 1998; 7(2): 69-78. doi: 10.1097/00006199199803000-00005

19. Hall JM, Stevens PE, Meleis Al. Marginalization: a guiding concept for valuing diversity in nursing knowledge development. Adv. Nurs. Sci. 1994; 16(4): 23-41. doi: 10.1097/00012272-199406000-00005

20. Wilson DW. Conceptualizing African American registered nurses as a vulnerable population. J. Multicult. Nurs. Health. 2003; 9(1): 61-67.

21. Ferrer RL, Palmer R. Variations in health status within and between socioeconomic strata. J. Epidemiol. Community. Health. 2004; 58(5): 381 387. doi: $10.1136 /$ jech.2002.003251

22. Leffers JM, Martins DC, McGrath MM, et al. Development of a theoretical construct for risk and vulnerability from six empirical studies. Res. Theory. Nurs. Pract. 2004; 18(1): 15-34. doi: 10.1891/rtnp.18.1.15.28060

23. Purdy IB. Vulnerable: a concept analysis. Nurs. Forum. 2004; 39(4): 25-33. doi: 10.1111/j.1744-6198.2004.tb00011.x

24. Glass N, Davis K. Reconceptualizing vulnerability: deconstruction and reconstruction as a postmodern feminist analytical research method. Adv. Nurs. Sci. 2004; 27(2): 82-92.

25. Jones PS, Zhang XE, Meleis Al. Transforming vulnerability. West. J. Nurs. Res. 2003; 25(7): 835-853.

26. Aday LA. Health status of vulnerable populations. Annu. Rev. Public Health. 1994; 15: 487-509.

27. Andrews $G$, Skinner D, Zuma K. Epidemiology of health and vulnerability among children orphaned and made vulnerable by HIV/AIDS in subSaharan Africa. AIDS. Care. 2005; 18(3): 8.

28. Galea $S$, Ahern J, Karpati A. A model of underlying socioeconomic vulnerability in human populations: evidence from variability in population health and implications for public health. Soc. Sci. Med. 2005; 60(11): 24172430. doi: 10.1016/j.socscimed.2004.11.028

29. Leavitt FJ. Is any medical research population not vulnerable?. Camb. $Q$. Healthc. Ethics. 2006; 15(1): 81-88. doi: 10.1017/\$0963180106060099 
30. Montes JJ, Johnston LL. Eliminating health disparities for vulnerable populations through health education interventions within health services programs.J. Health. Educ. 1998;29(5):2.doi:10.1080/10556699.1998.10603390

31. Ramanna H, DeBakker JM, Elvan A, Hauer, RN. On the atrial response to focal discharges in man. J. Cardiovas. Electrophysiol. 2004; 15(6): 629-636. doi: 10.1046/j.1540-8167.2004.03436.x

32. Scheinkman M, Fishbane MD. The vulnerability cycle: working with impasses in couple therapy. Fam. Process. 2004; 43(3): 279-299. doi: 10.1111/j.1545-5300.2004.00023.x
33. Stevens $P$, Hall JM, Meleis Al. Examining vulnerability of women clerical workers from five ethnic/racial groups. West. J. Nurs. Res. 1992; 14(6): 754-774.

34. Hall JM, Stevens PE, Meleis Al. Marginalization: a guiding concept for valuing diversity in nursing knowledge development. Adv. Nurs. Sci. 1994; 16(4): 23-41. doi: 10.1097/00012272-199406000-00005

35. Hall JM. Marginalization revisited: critical, postmodern, and liberation perspectives. Adv. Nurs. Sci. 1999; 22(2): 88-102. doi: 10.1097/00012272199912000-00009

36. The Nursing Process. American Nurses Association, 2017. 